\title{
Case Study on Early Age Shrinkage of Cement- based Composites
}

\author{
Andina Sprince, Leonids Pakrastinsh \\ Riga Technical University, Department of Structural Engineering. Address: Azenes Street 16, \\ Riga, LV-1048, Latvia.
}

\begin{abstract}
The aim of this paper was to study the behaviour of new high-performance fibre-reinforced cement composite materials (FRCC) that are reinforced with polyvinyl alcohol (PVA) fibres. The shrinkage deformations at early age, the compressive strength and modulus of elasticity of the new compositions had been determined. Test results shows that the addition of PVA fiber $1.10 \%$ and $0.55 \%$ by weight of the cement has negligible influence on concrete drying shrinkage, however, it is affect the concrete plastic and autogenous shrinkage. The results of the experiments permitted the prediction of long-term deformations of the concrete. Wider use of this material permit the construction of sustainable next generation structures with thin walls and large spans that cannot be built using the traditional concrete.
\end{abstract}

Keywords - cement-based matrix, fibre reinforced concretes, high performance concretes, PVA fibres, shrinkage

\section{INTRODUCTION}

Concrete shrinkage is a non-elastic deformation in plastic and hardened state that progresses with time and may cause displacement or deflection of a structural element, loss of preliminary tension, redistribution of stresses, as well as reduction of shear resistance in regions with small moments. Restricted concrete shrinkage can also cause development and growth of cracks, which may lead to operation and serviceability problems. Therefore, when designing structures, the designer must provide for the control of shrinkage stresses and the resulting cracks in a restricted concrete element.

Plastic shrinkage cracks appear after the concrete has been cast but before it has gained strength. Nowadays the most popular method for controlling plastic shrinkage cracks is use of synthetic fibres in the amounts ranging from $0.05 \%$ to $0.5 \%$. Synthetic fibres were first used already in the end of the 1960s. Although all synthetic fibres have similar advantages, polyvinyl alcohol (PVA) fibres were used for this study due to their larger tensile strength and modulus of elasticity, as well as good bonding with concrete. The study concentrates on determining the effect of PVA fibres on concrete shrinkage and cracking.

There have been extensive investigations that prove that the use of PVA fibres substantially reduces the plastic shrinkage of concrete (early age shrinkage) and the development of related cracks [1], [2]. In these studies PVA fibres have also been compared to other synthetic fibres.

Plastic shrinkage starts in concrete already within the first few hours after it has been cast into the mould. It is because the concrete mass starts to lose its free moisture, and the rate of evaporation exceeds the rate of bleeding. And if the tensile strength of bonded concrete is insufficient, plastic shrinkage cracks appear. Especially susceptible to plastic shrinkage are structures with a large surface area that is subjected to the environment, e.g. concrete paving, bridge decks, walls, etc.

It was observed that non-reinforced concrete exhibited slow shrinking in the first 30 minutes, but after 1.5 to 4 hours the shrinkage increased rapidly. However, when the amount of free moisture is reduced due to evaporation and the concrete is simultaneously hydrated, it becomes firmer. As a result, when concrete begins to harden, the increase of the plastic shrinkage rate remains minimal. After this period concrete shrinkage stabilizes almost completely. In the first few hours, non-reinforced concrete behaves much in the same way as concrete with PVA fibres, but after that non-reinforced concrete starts to shrink more intensively. In this study, by using PVA fibres, the plastic shrinkage in concrete was reduced by $36.20 \%$. It was also proved that an increase of fibre content from $0.1 \%$ to $0.4 \%$ has minimum impact on reducing the shrinkage. Therefore, to reduce plastic shrinkage, it is enough to use $0.1 \%$ of PVA fibres. In addition, the difference in fibre parameters, moduli of elasticity, lengths, diameters and bonding with concrete do not have significant effect on plastic shrinkage of concrete. Nevertheless, PVA fibres achieve slightly better results than plypropylene and carbon fibres. The drying shrinkage is so large because the experiment provided favourable conditions for plastic shrinkage and the concrete was not cured [1].

One of the reasons why synthetic fibres such as PVA are so effective in reducing the plastic shrinkage in concrete was explained by Mangat and Azari [3]. When the concrete structure is subjected to tensile stresses caused by shrinkage, the fibres reduce the shrinkage because of the shear between the surface of the fibre and the concrete. In addition, the fibres increase the strength and rigidity of the concrete structure. For these reasons, PVA fibres are an 
effective solution for reducing the plastic shrinkage in concrete by $40 \%$, as well as limiting the cracking (literature indicates reduction of up to $90 \%$ ).

Unlike plastic shrinkage, drying shrinkage takes place only after the concrete has hardened. Drying shrinkage develops for a long time and when it is restricted, it can cause significant cracking of the structure both before and after loading. Addition of PVA fibres in the amounts ranging from 0 to $0.2 \%$ cannot limit the cracks caused by drying shrinkage, though it can reduce the cracking caused by plastic shrinkage.

Development of drying shrinkage cracks can be effectively limited by increasing the fibre content [4], [5]. In this experiment, the amount of PVA fibres was increased to $0.5 \%$, and established that PVA (F45) micro fibres can reduce the width of the cracks by $90 \%$, while PVA macro fibres can reduce it by $70 \%$. Therefore, smaller fibre dimensions and a larger fibre content help increase the total surface area of fibres that is in contact with the concrete structure. This permits better distribution of stresses in the space between the cracks and more effectively limits the crack width.

Adding $0.5 \%$ of PVA fibres (both macro F45, and micro F200) had only a slight impact on reducing the drying shrinkage. Macrofibres F45 show better results in reducing the drying shrinkage, which could be explained with the fact that fibres might change the interior water circulation in the concrete structure. However, this reduction of shrinkage was not sufficient to relieve the stresses [4].

In the last few years infrastructure projects have seen a rise in the application of concrete with improved characteristics. Such high performance fibre-reinforced concrete HPFRCC (high performance fibre reinforced cement compositehidra) has high strength and durability, low permeability and good casting properties. These characteristics permit the construction of larger spans, thinner and more geometrically complicated structures, while simultaneously ensuring better durability and sustainability.

However, concrete shrinkage and permeability are factors that have major influence on the durability of the concrete. Such high-strength concretes (in this case the pressure strength of the samples reached even $200 \mathrm{MPa}$ ) have low porosity and high cement content, which causes increased autogenous shrinkage, because the concrete is losing water due to hydration even though it is kept moist from the outside. Although such cement has a low W/C ratio, it usually contains small particles $(\max 5 \mathrm{~mm})$, therefore drying shrinkage is also important for HPFRCC mixes. The linear deformation data obtained in this study include both autogenous and drying shrinkage.

As described above, fibres in high-performance concretes ensure an increase of tensile strength, the control of crack width, as well as uniform distribution of cracks. In concretes with traditional strength parameters the fibres ensure control of the shrinkage cracks and reduced deformation. However, studies regarding the effect of fibres on high-performance concrete shrinkage are not so straightforward, except as concerns plastic shrinkage (not investigated in this study) where it is effective to use fibres.

This study concentrates on the effect of PVA fibres on the drying and autogenous shrinkage of highperformance fibre-reinforced concrete. it is planned to use such concrete also for the cast in-situ reinforced concrete walls of a wood drying plant, which serves also as an engineer's qualification work. A highstrength fibre-reinforced concrete was selected because the structure will be subjected to aggressive conditions (high humidity, cyclic temperature changes), it has large surface area $(7.6 \mathrm{~m} \times 16 \mathrm{~m})$ and unevenly distributed tensile shrinkage stress is expected, because both sides of the walls will be subjected to different environmental conditions. For these reasons, it would be more effective to use fibres, in addition to metal reinforcement, to control the cracks caused by tensile stresses. PVA fibres will be used, because metal fibres might corrode due to the aggressive environment, and PVA fibres also have better tensile strength and modulus of elasticity, as well as an excellent bonding ability with concrete in comparison with other chemical fibres. It is worth noting that PVA (polyvinyl alcohol) fibres are more economical.

In this way, by changing the PVA fibre content from $0 \%$ to $0.56 \%$ and $1.1 \%$, this study investigates the effect on autogenous and drying shrinkage of highperformance concrete.

\section{MATERIALS AND METHODS}

Three different high-strength concrete mixes were prepared for this study. The compositions differ by their fibre content; see Table 1.

TABLE 1

CONCRETE MIX COMPOSITIONS

\begin{tabular}{|lllll|}
\hline Materials & & 1 mix & 2 mix & 3 mix \\
\hline & $\begin{array}{l}\text { E } \\
\text { (reference } \\
\text { mix) }\end{array}$ & $\begin{array}{l}\text { PVA- } \\
0.6\end{array}$ & $\begin{array}{l}\text { PVA- } \\
0.8\end{array}$ \\
\hline Cement I 42.5 N & $\mathrm{kg} / \mathrm{m}^{3}$ & 675 & 675 & 675 \\
\hline Cement I $52.5 \mathrm{~N}$ & $\mathrm{~kg} / \mathrm{m}^{3}$ & 225 & 225 & 225 \\
\hline $\begin{array}{l}\text { Sand 0/1 from } \\
\text { Saulkalne }\end{array}$ & $\mathrm{kg} / \mathrm{m}^{3}$ & 300 & 300 & 300 \\
\hline $\begin{array}{l}\text { Sand 0/2.5 from } \\
\text { Saulkalne }\end{array}$ & $\mathrm{kg} / \mathrm{m}^{3}$ & 300 & 300 & 300 \\
\hline $\begin{array}{l}\text { Diabase 0/5 } \\
\mathrm{kg} / \mathrm{m}^{3}\end{array}$ & 200 & 200 & 200 \\
\hline $\begin{array}{l}\text { Diabase } 2 / 5 \\
\mathrm{~kg} / \mathrm{m}^{3}\end{array}$ & 200 & 200 & 200 \\
\hline $\begin{array}{l}\text { Ground silica } \\
8 \text { min. }\end{array}$ & $\mathrm{kg} / \mathrm{m}^{3}$ & 100 & 100 & 100 \\
\hline Microsilica 920 D & $\mathrm{kg} / \mathrm{m}^{3}$ & 100 & 100 & 100 \\
\hline
\end{tabular}




\begin{tabular}{|lllll|}
\hline Water & $\mathrm{kg} / \mathrm{m}^{3}$ & 200 & 200 & 200 \\
\hline Superplast. HE-30 & $\mathrm{kg} / \mathrm{m}^{3}$ & 24 & 24 & 24 \\
\hline PVA fibres & $\mathrm{kg} / \mathrm{m}^{3}$ & 0 & 5 & 10 \\
\hline W/C & & 0.22 & 0.22 & 0.22 \\
\hline
\end{tabular}

Since this is a high-strength concrete, it has a small $\mathrm{W} / \mathrm{C}$ ratio - only 0.22 . It is smaller than the theoretical ratio 0.24 , which is required for hydration of all cement. In this case the non-hydrated cement particles serve as aggregate [6].

Two different cements were used as a bonding agent - CEM I $42.5 \mathrm{~N}$ and CEM I $52.5 \mathrm{~N}$, where CEM I indicates the type of cement, which in this case is Portland cement without additives. It consists and is made of only rock gypsum and common Portland cement clinker, without any special strengthincreasing additives. The numbers 42.5 and 52.5 indicate the pressure strength $\left(\mathrm{N} / \mathrm{mm}^{2}\right)$ of a sample after 28 days of hardening in standard conditions, while letter $\mathrm{N}$ means that this is a normal setting cement - after two days of hardening in standard conditions its strength must be at least $10 \mathrm{~N} / \mathrm{mm}^{2}$.

The aggregate was washed quartz sand with fractions of $0 / 1 \mathrm{~mm}$ and $0 / 2.5 \mathrm{~mm}$, and crushed diabase with fractions of $0 / 5 \mathrm{~mm}$ and $2 / 5 \mathrm{~mm}$. Aggregate fractions were minimized and did not exceed $5 \mathrm{~mm}$. Smaller aggregate particles increase the surface area between the aggregate and the cement and reduces the development of microcracks [6].

By content the fibres account for $0.56 \%$ and $1.1 \%$ of cement mass. In this study only PVA fibres were used. The first reason was that metal fibres could start corroding in the high humidity conditions described. The second reason was that although PVA fibres have the same advantages as other synthetic fibres, their tensile strength and modulus of elasticity are much higher, besides PVA fibres have a very good ability to bond with cement paste [7], [8]. The mechanical properties and dimensions of the PVA fibres used in the study are presented in Table 2 .

TABLE 2

MECHANICAL PROPERTIES AND DIMENSIONS OF PVA FIBRES

\begin{tabular}{|lllll|}
\hline Fibre type & $\begin{array}{l}\text { Length, } \\
\mathrm{L}(\mathrm{mm})\end{array}$ & $\begin{array}{l}\text { Diametre, } \\
\mathrm{D}(\mu \mathrm{m})\end{array}$ & $\begin{array}{l}\text { Tensile } \\
\text { strength } \\
(\mathrm{MPa})\end{array}$ & $\begin{array}{l}\text { Mod. of } \\
\text { elasticity } \\
(\mathrm{MPa})\end{array}$ \\
\hline MC 40/8 & 8 & 40 & 1600 & 42000 \\
\hline
\end{tabular}

To improve the casting properties of the mixes, considering the low $\mathrm{W} / \mathrm{C}$ ratio 0.22 , and to ensure uniform distribution of the fibres, superplasticizer HE30 was added to the mix. To improve the properties of the concrete, Microsilica 920 D (densified silica fume) was added to the mix. This has dual effect - physical and chemical. It fills the voids between larger particles and ensures a denser structure, and a pozzolanic reaction takes place when silicic acid reacts with calcium hydroxide resulting in calcium silicate hydrate, which is stronger.

The mixing of the sample mixes, their moulding, curing and measuring was carried out in accordance with the European standard EN 12617-4 "Determination of shrinkage and expansion".

Non-restricted linear free shrinkage of concrete was measured using the first measurement method. For this purpose, prism samples of $40 \mathrm{~mm} \times 40 \mathrm{~mm} \times 160 \mathrm{~mm}$ were required. Their shrinkage was measured in the time period from 24 hours to 56 days after casting into the mould.

The concrete mix was prepared in the laboratory in a vertical mixer. First, the aggregates and water were mixed, then the chemical and artificial mineral additives and fibres were added, and then the mix was mixed once more. After that the concrete was cast into moulds, and all moulds were filled and vibrated in the same manner; the top of the sample was levelled with a trowel if required.

Then the samples were covered with a film for 24 hours and left to harden, after that they were demoulded. The samples were cured by placing them in water basins.

Once the samples are removed from the basin and the measurement of shrinkage begins, nail-like stainless steel elements with rounded heads are attached (glued) to both ends of the sample. They must be placed directly on the central axis. It is necessary in order to make precise shrinkage measurements.

TABLE 3

SAMPLE TYPES DEPENDING ON THE DURATION OF CURING

\begin{tabular}{lllll}
\hline \multirow{2}{*}{ Mix } & \multicolumn{2}{l}{ Duration of sample curing } & \\
\cline { 2 - 5 } & 1 day & 4 days & 7 days & 14 days \\
\hline 1 & PVA-E-4 & PVA-E-9 & PVA-E-12 & PVA-E-18 \\
mix & PVA-E-5 & PVA-E-10 & PVA-E-16 & PVA-E-20 \\
& & & & \\
\hline 2 & PVA-0.6-4 & PVA-0.6-9 & PVA-0.6-11 & PVA-0.6-19 \\
mix & PVA-0.6-5 & PVA-0.6-10 & PVA-0.6-15 & PVA-0.6-20 \\
& & & & \\
\hline 3 & PVA-0.8-3 & PVA-0.8-20 & PVA-0.8-14 & PVA-0.8-6 \\
mix & PVA-0.8-4 & PVA-0.8-24 & PVA-0.8-16 & PVA-0.8-26
\end{tabular}

The temperature in the laboratory must be $21 \pm 2^{\circ} \mathrm{C}$, and the humidity must be $60 \pm 10 \%$. In this study the samples were cured for different periods: 1 day, 4 days, 7 days and 14 days; see Table 3. After the curing the samples were kept in the laboratory in standard conditions, and their shrinkage was measured.

Before measuring the length of the samples, the ambient humidity and temperature in the laboratory must be noted on the record sheet. The length of the samples is measured with a gauge measurement tool (shrinkage clamp) calibrated to a sufficient length in order to measure the minimum length of the sample \pm $5 \mathrm{~mm}$ with a precision of $\pm 0.001 \mathrm{~mm}$. The shrinkage clamp must have tight contact with the sample and its 
axis of measurement must directly coincide with the axis of the sample (clamp jaws directly on the rounded steel elements glued to the sample). The shrinkage clamp used in this study is shown in Fig. 1.

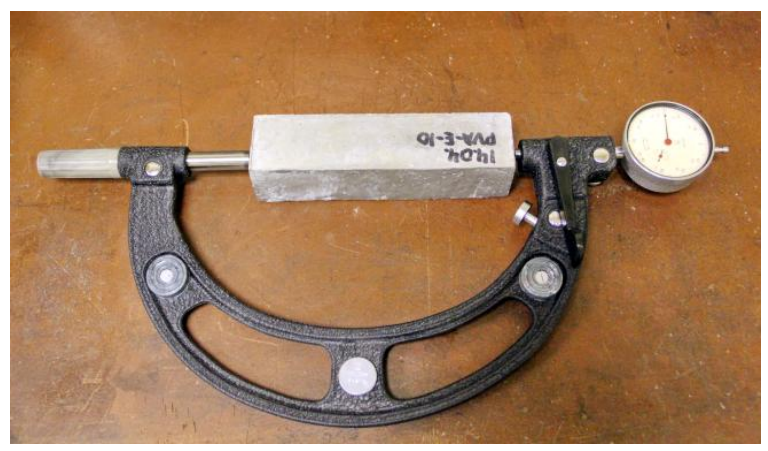

Fig. 1. Shrinkage clamp

The drying shrinkage of a sample is a displacement deformation exhibited as a change of length in relation to the initial length. Each time when the concrete shrinkage is measured, it is recommended to measure also the weight changes, as it signifies changes in the density of the sample.

\section{RESULTS AND DISCUSSION}

Since the properties of freshly cast concrete can be easily influenced by different factors, such as the mixing procedure and environmental conditions, small variations may cause differences in the experimental results. The values shown in the graphs below are the average values of two simultaneously cast samples. The differences between the same mixing and curing procedure samples at each test were within a 5-13\% limit.

As mentioned before, the samples were left to harden for 24 hours and then subjected to curing for different periods of time. The measurement of the shrinkage deformations of samples subjected to only 1 or 4 days of curing include both drying and autogenous shrinkage deformations. Since autogenous shrinkage occurs only in the first few days, in samples that were cured for 7 and 14 days hydration had already completed and autogenous shrinkage constitutes only an minor portion of the linear shrinkage deformation.

The results illustrating the effect of PVA fibres on the unrestrained shrinkage of high-strength concrete are shown in Fig. 2 to 5. As seen in the graphs, PVA fibres have minimum impact on shrinkage of the concrete. All graphs show a common tendency, except for the mix that was cured for 4 days, namely, mix compositions with a PVA fibre content of $0.56 \%$ shrink as much or slightly less that the reference mix without any PVA fibres, while the mix containing $1.1 \%$ of PVA fibres is shrinking more than the reference mix. The shrinkage deformation shown in Fig. 3 is different from the other measurements in that the reference mix exhibits more shrinkage than both mixes with PVA fibres, and the difference reaches even $15.5 \%$. However, these results may reflect the influence of PVA fibres imprecisely, as the average value of the reference mix might be imprecise - the difference between the first and second reference sample was $13 \%$, and the second sample exhibited te same shrinkage as the mix with PVA fibre content of $0.56 \%$.

TABLE 4

FREE DRYING SHRINKAGE FOR CONCRETES WITH DIFFERENT

PVA FIBRE CONTENT IN COMPARISON WITH REFERENCE CONCRETE WITHOUT FIBRES AT 35 DAYS

\begin{tabular}{llll}
\hline $\begin{array}{l}\text { Curing } \\
\text { period }\end{array}$ & $V_{f}(\%)$ & $\begin{array}{l}\text { Shrinkage } \\
\text { deformation } \\
\varepsilon\left(\times 10^{-6}\right)\end{array}$ & $\begin{array}{l}+/ \text { - (increase/ } \\
\text { reduction)\% }\end{array}$ \\
\hline \multirow{4}{*}{1 day } & 0.00 & 982.1 & \\
& 0.56 & 1000.0 & +1.79 \\
& 1.11 & 1089.3 & +9.84 \\
\hline \multirow{4}{*}{4 days } & 0.00 & 803.6 & \\
& 0.56 & 678.6 & -15.5 \\
& 1.11 & 767.9 & -4.4 \\
\hline \multirow{4}{*}{7 days } & 0.00 & 675.0 & \\
& 0.56 & 628.6 & -6.87 \\
& 1.11 & 785.7 & +14.1 \\
\hline \multirow{4}{*}{14 days } & 0.00 & 482.1 & \\
& 0.56 & 517.9 & +6.9 \\
\hline
\end{tabular}

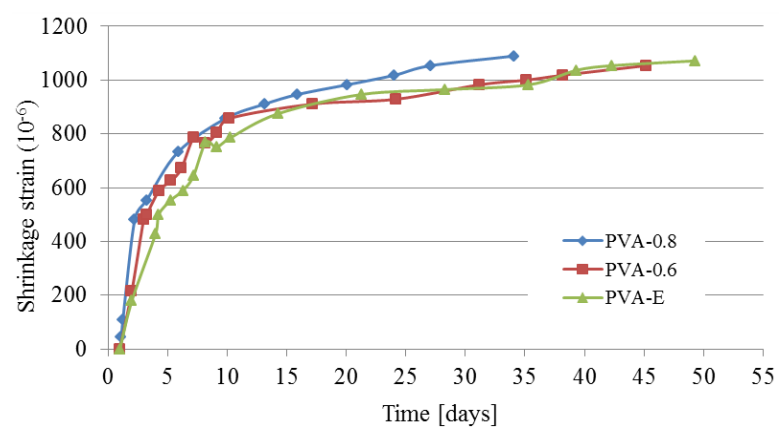

Fig. 2. Unrestrained shrinkage in concrete with different PVA fibre content after 1 day of curing

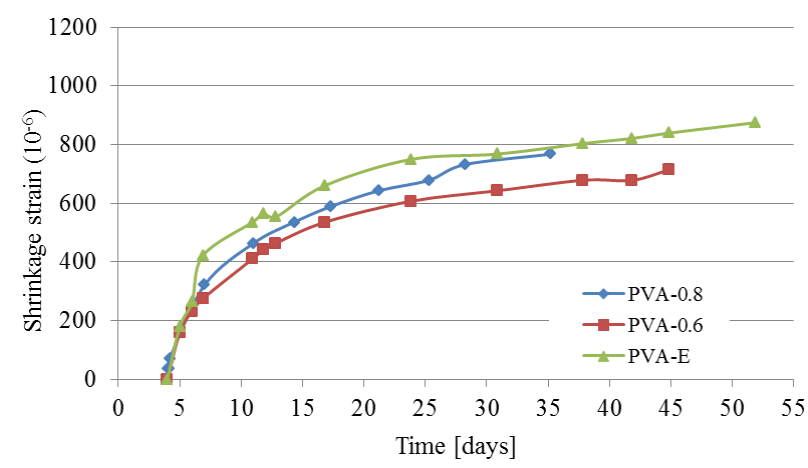

Fig. 3. Unrestrained shrinkage in concrete with different PVA fibre content after 4 days of curing 


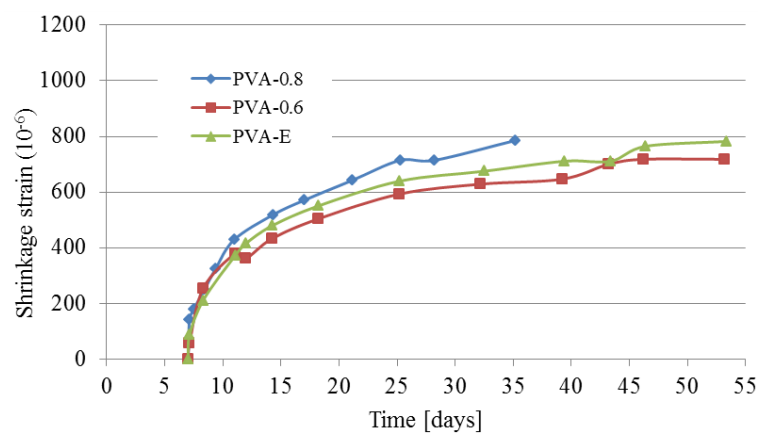

Fig. 4. Unrestrained shrinkage in concrete with different PVA fibre content after 7 days of curing

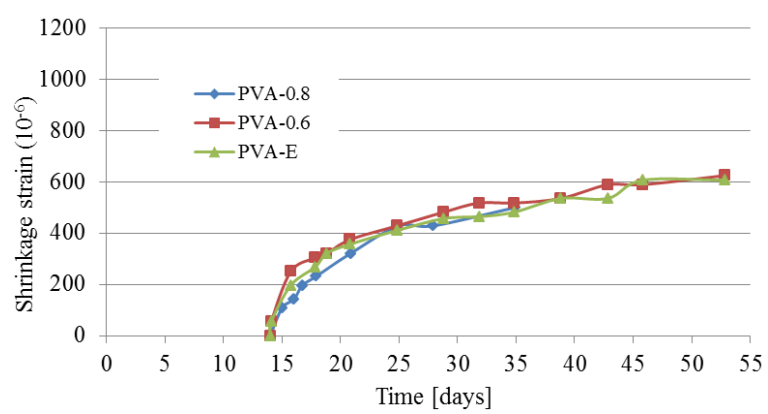

Fig. 5. Unrestraibed shrinkage in concrete with different PVA fibre content after 14 days of curing

The obtained data vary, therefore, in order to draw conclusions regarding the effect of fibres on concrete shrinkage, the moisture loss (weight reduction) of the concrete samples was measured and compared taking into consideration the different mix compositions, because both autogenous and drying shrinkage occurs by loss of water.
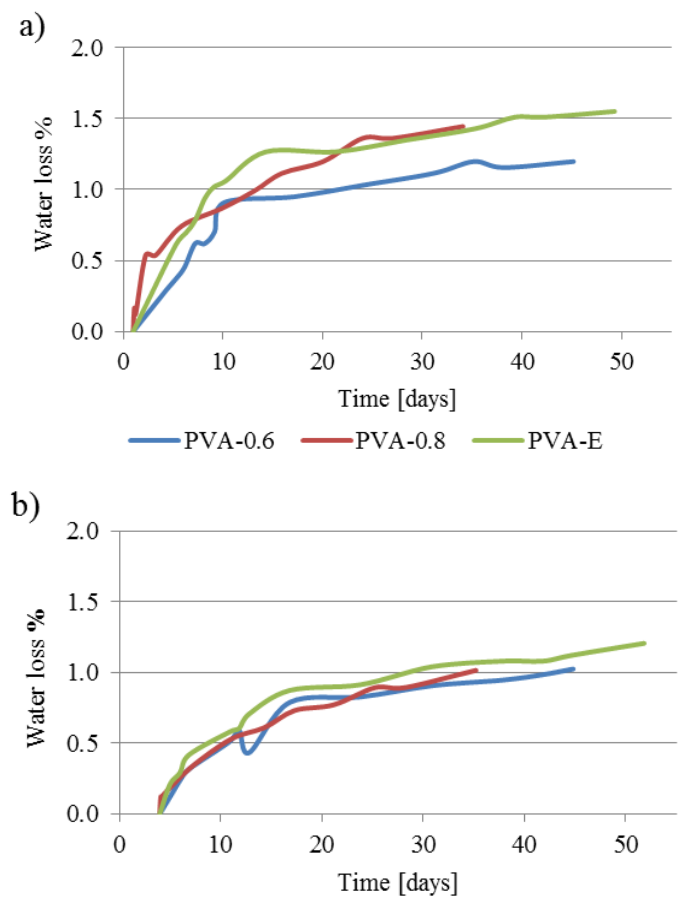

$\longrightarrow$ PVA-0.6 PVA-0.8 PVA-E
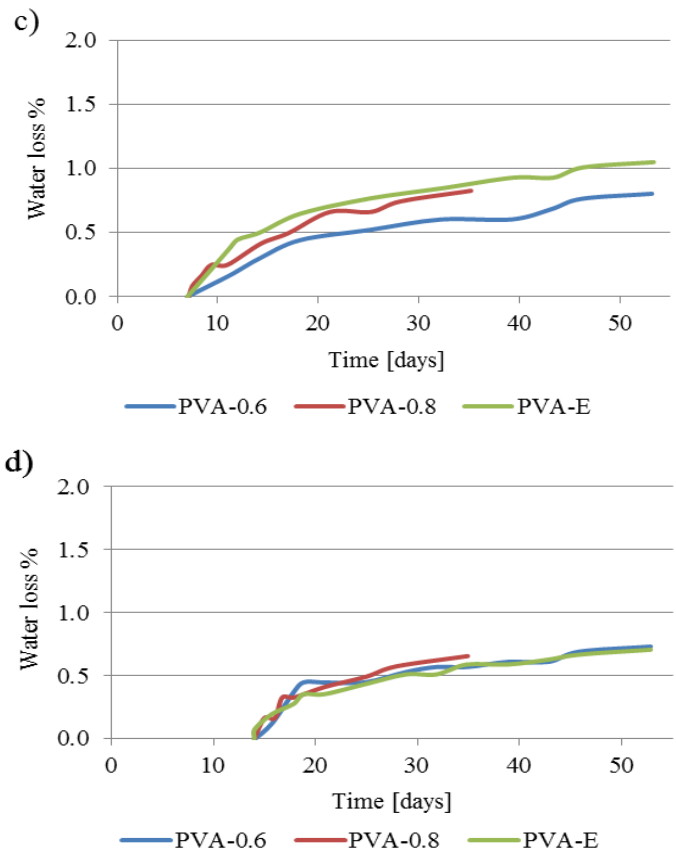

Fig. 6. Relative water loss vs time in concrete with different PVA fibre content and different curing periods: a) at 1 day; b) at 4 days; c) at 7 days; d) at 14 days

The moisture loss curves reflect the shrinkage deformations of the concrete samples, and it can be concluded that PVA fibres $(0.56 \%)$ help reduce shrinking in concrete if the concrete is cured for 1 to 7 days. This in turn may prove that with the help of PVA fibres it is possible to reduce the autogenous shrinkage in concrete (2-10\%), but, as shown in Fig. 4 and 5, PVA fibres have virtually no effect on drying shrinkage.

Unlike in other studies, the increase of fibre content from $0.56 \%$ to $1.1 \%$ did not reduce the shrinkage; quite the contrary - it increased in comparison with the reference sample, even though a fibre content of $1.1 \%$ (PVA-0.8) slightly reduces the moisture loss in comparison with that of the reference sample; see Fig. 6. Considering that in high-performance concretes the fibre content is $1.5 \%$ to $5 \%$, and the obtained results are in contradiction with similar studies [1] and [8], the fibre content of the composition should be changed (to, e.g. $2 \%$ ) to achieve clear results.

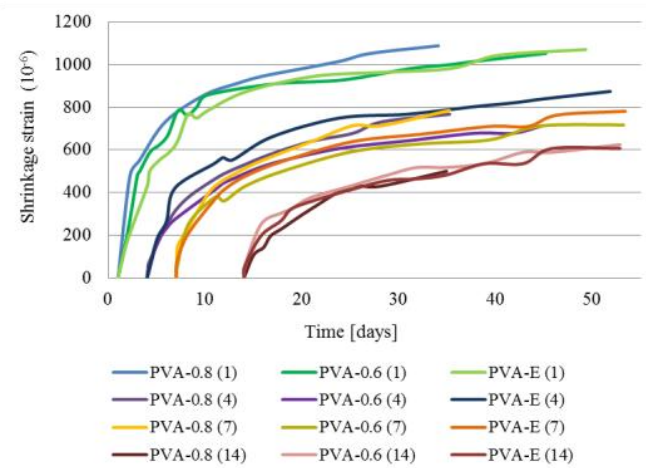

Fig. 7. Unrestrained shrinkage of concrete depending on the duration of curing 
In Fig. 6 it is evident that the shorter is the curing period, the larger is the moisture loss. If concrete is cured for 4 days, the moisture loss may be reduced by $23 \%$; for 7 days - by $33 \%$ and for 14 days - by $46 \%$. As a result the concrete loses less water and the concrete shrinkage is consequently smaller; see Fig. 7, which shows that the shrinkage at 50 days with 1 day of curing is -1100 ; with 4 days of curing it is -800 ; with 7 days of curing -700 , and with 14 days of curing -600 (all values $\times 10^{-6}$ ). However, samples that have been cured for more than one day, already have undergone some autogenous shrinkage, which is not reflected in these graphs. Since this is highperformance concrete, its autogenous shrinkage constitutes a substantial part of the linear deformation. For this reason, the obtained results cannot be attributed solely to the drying shrinkage, and in reality the samples may exhibit larger deformations. Therefore, it would be useful to perform a separate autogenous shrinkage test to determine just how effectively PVA fibres can influence the chemical shrinkage of concrete (moisture loss due to cement hydration), which for high-performance concretes is quite substantial. To obtain clearer results it would also be necessary to increase the number of samples.

\section{CONCLUSIONS}

Experimental shrinkage tests of high-performance fibre-reinforced concretes with different content of polyvinyl alcohol (PVA) fibres $-0.56 \%$ and $1.1 \%$ of cement mass — were carried out in the RTU laboratory and compared with the data from reference mix. The obtained shrinkage test results indicate that addition of PVA fibres to high-performance concrete does not have substantial effect on its shrinkage.

Since this was a high-strength concrete, the autogenous shrinkage in the first few days constitutes a major part of the linear deformation. Therefore the obtained results cannot be attributed solely to the drying shrinkage.

Samples that have been cured for more than four days, already have undergone some autogenous shrinkage which is not reflected in these shrinkage results. Therefore, in samples that have been cured for more than one day, the resulting deformation does not reflect the true shrinkage deformation of these samples. To find the final shrinkage deformation of PVA fibre-reinforced concrete, as well as the effect of PVA fibres on the autogenous shrinkage, it would be necessary to continue the experiment by performing a separate autogenous shrinkage test.

The moisture loss results reflect the shrinkage deformations of the concrete, and it can be concluded that PVA fibres $(0.56 \%)$ help reduce shrinking in concrete if the concrete is cured for 1 to 7 days, which in turn may prove that with the help of PVA fibres it is possible to reduce the autogenous shrinkage in concrete $(2-10 \%)$, since in samples cured for 14 days the fibres have no effect on the moisture loss. Thus it can be concluded that PVA fibres are not an effective solution for reducing the shrinkage in concrete.

The results of the moisture loss measurements reflect the evident connection that the shorter is the curing period, the larger is the moisture loss. If concrete is cured for 4 days, the moisture loss may be reduced by $23 \%$; for 7 days - by $33 \%$ and for 14 days — by $46 \%$. By reducing the moisture loss, shrinkage is also reduced.

It can be presumed that the use of PVA fibres might be justified in cases where shrinkage deformation is exhibited by a restricted concrete element and where PVA fivres could help control the crack propagation and quantity, their width and distribution. This could be a direction of further research.

In future experiments the researchers could also change the PVA fibre content $(2 \%)$, combine PVA macro and micro fibres or different fibre materials, e.g. cellulose.

\section{REFERENCES}

[1] Wongtanakitcharoen T., Naaman A. E. Unrestrained early age shrinkage of concrete with polypropylene, PVA, and carbon fibers. Materials and structures Vol. 40, No 3, 2007, pp. 28930. doi:10.1617/s11527-006-9106-z.

[2] Fischer G., Li V. 2007. Effect of fiber reinforcement on the response of structural members. Engineering Fracture Mechanics, Vol. 74, 2007. pp. 258-272. doi:10.1016/j.engfracmech.2006.01.027.

[3] Mangat P. S., and Azari M. M. A theory for the free shrinkage of steel fiber reinforced cement matrices. J. Mat. Sci., 19, 1984, pp. 2183-3194.

[4] Passuello A., Moriconi G., .Shah S. P. Cracking behavior of concrete with shrinkage reducing admixtures and PVA fibers. Cement and Concrete Composites, Volume 31, Issue 10, November 2009, pp. 699-704. doi:10.1016/j.cemconcomp.2009.08.004.

[5] Pease, B. J, Shah, H, Hossain, A. \& Weiss, J. Restrained Shrinkage Behavior of Mixtures Containing Shrinkage Reducing Admixtures and Fibers, in: ICACS 2005 International Conference on Advances in Concrete Composites and Structures, Chennnai, India, January 6th-8th 2005, 265-274.

[6] Justs J., Shahmenko G. Effect of Mix Proportions and Curing Regimes on Ultra High Performance Concrete. Proceedings of 8th FIB International Symposium in Civil Engineering, Denmark, Lyngby, 20.-23. June, 2010, pp 425-430.

[7] Toutanji H., Xu B., Gilbert H., Lavin T. Properties of polyvinyl alcohol fiber reinforced high-performance organic aggregate cementitious material: Converting brittle to plastic. Construction and Building Materials, Volume 24, Issue 1, January 2010, pp. 1-10. doi:10.1016/j.conbuildmat.2009.08.023.

[8] Sun W., Chen H., Luo X., Qian H. The effect of hybrid fibers and expansive agent on the shrinkage and permeability of high-performance concrete. The Department of Materials Science and Engineering, Southeast University, China, 2000. 